\title{
An ethical assessment of low carbon vehicles using cost benefit analysis
}

\section{Nikolas Thomopoulos*}

Department of Systems Management and Strategy,

University of Greenwich,

London, SE10-9LS, UK

Email: n.thomopoulos@greenwich.ac.uk

*Corresponding author

\section{Gillian Harrison}

Energy Research Institute,

University of Leeds,

Woodhouse Lane, LS2-9JT, UK

Email: drgillianharrison@gmail.com

\begin{abstract}
Global concerns about climate change, as confirmed at COP21, have led to lower carbon emissions environmental policies, particularly in the road transport sector. Through an empirical analysis of low carbon vehicle (LCV) policies in California, this paper contrasts the findings from diverse distribution theories between income quintiles - used as a proxy for societal groups - to address vertical equity concerns and offer an overview of impact distribution to policy makers. Thus, it contributes in operationalising ethical theories within transport cost benefit analysis and revisiting impact distribution when promoting low carbon vehicles. Findings indicate that manufacturer penalties are the most effective policy measure to avoid cost transfer between stakeholders. Yet, the analysis shows that those purchasing small LCVs may face disproportional vehicle purchase cost increases which needs to be considered by policy makers. Thus, this paper makes a methodological contribution regarding $\mathrm{CBA}$ in practice as well as providing policy relevant recommendations.
\end{abstract}

Keywords: low carbon vehicles; LCVs; cost benefit analysis; CBA; California; ethics; assessment; car manufacturer; regulation; subsidies.

Reference to this paper should be made as follows: Thomopoulos, N. and Harrison, G. (2016) 'An ethical assessment of low carbon vehicles using cost benefit analysis', Int. J. Automotive Technology and Management, Vol. 16, No. 3, pp.227-247.

Biographical notes: Nikolas Thomopoulos is a Senior Lecturer in Transport and Business Logistics at the University of Greenwich and contributed to a range of European and international research projects. He has co-edited the book ICT for Transport: Opportunities and Threats and previously was the Chair of a RSA research network on using ICT to facilitate 'smart' and 'green' regional growth. His research interests include transport innovation and strategic evaluation. 
Gillian Harrison received her PhD from the University of Leeds, Energy Research Institute. Her interdisciplinary research combined system dynamic modelling, engineering and moral philosophy in the appraisal of policy options for the uptake of low carbon vehicle technologies. She is currently a Research Fellow in Electro-Mobility Modelling at the Institute for Energy and Transport, Joint Research Centre of the European Commission, based in the Netherlands. Her research interests in addition to modelling are focussed around sustainable and equitable transport policy solutions in a carbon-constrained and automobile-centric society. The views expressed are purely those of the author and may not in any circumstances be regarded as stating an official position of the European Commission.

\section{Introduction}

The use of cost benefit analysis (CBA) has been dominating transport policy appraisal for several decades in developed countries, particularly in Europe (Odgaard et al., 2005; Mackie and Worsley, 2013). Despite the ongoing diffusion of ICT to improve data accuracy in a lot of sectors including transport (Thomopoulos et al., 2015), this prevailing position appears not to have been significantly challenged yet due to the virtues of CBA (Eliasson and Lundberg, 2012; Mackie, 2011), though this method has been subject to an increasing debate in the realm of other sectors such as healthcare (Folland et al., 2007). Nevertheless, certain criticisms of CBA practice remain unresolved as highlighted in the literature (Beukers et al., 2012; ITF, 2011; Mouter et al., 2013b, 2015; Thomopoulos et al., 2009; van Wee, 2011; Vickerman, 2007).

One of the major criticisms of CBA revolves around impact quantification and monetisation (Mackie and Preston, 1998), whereas another key one is about the assessment of impact distribution. Wider economic impacts, equity and other non-monetised impacts are not included formally in the appraisal and are not considered explicitly by decision makers since they form part of separate tables which are not incorporated in the benefit-cost ratio (BCR) (Mackie and Worsley, 2013). These are not excluded per se from conventional CBA (van Wee, 2012), yet impact distribution often does not form a key part of the analysis. The latter issue is intertwined with equity and ethical issues which are implicitly addressed when implementing a utilitarian-based approach. It is acknowledged here that not all transport policies include equity as one of their explicit objectives, although issues such as climate change or environmental pollution are directly relevant since the whole of the population in a given geographical area is affected. Hence, equity concerns and ethics are intertwined with impact distribution due to their implicit inclusion in the welfare maximisation objective of CBA, which forms an identified weakness of this appraisal method in practice (Thomopoulos et al., 2009).

As already pointed out, both the contents and process of CBA should be improved to aid transport appraisal overall (Beukers et al., 2012; van Wee, 2012), potentially focusing more on the actual role of this widely used method which could be more subtle (Mouter et al., 2013a). Alternative approaches and theories may be used within a wider appraisal framework having CBA at its core (Annema et al., 2015; Thomopoulos, 2010). Such an approach would utilise the strengths of CBA while addressing some of its weaknesses. This would also satisfy the requirement set out by Roeser (2012) according to which 
policy makers "should not be unemotional calculators [...] but through a cultivation of their moral emotions and sensitivity engage in more responsible decision making", since "we need emotions to make a rational decision" (Roeser, 2006). Along the same lines, this paper demonstrates that alternative approaches can and should be tested in practice to enhance the assessment of impact distribution among diverse socio-economic groups. This objective can be met through case studies, so the aim of this paper is accomplished through an application of a system dynamics model (Walther et al., 2010; Harrison and Shepherd, 2014) providing the input to improve the contents and prospects of CBA (Turner, 2007).

Previous research has focussed on aggregate policy impacts of biofuels, electric vehicles or other emission reduction schemes (Ghermandy et al., 2013; Marsden and Hess, 2011; Oxley et al., 2012; Podhora et al., 2013; Rode et al., 2014), but not on impact distribution among societal groups. Therefore, this paper contrasts findings between household income quintiles used as a proxy for societal groups to extend previous findings and offer an overview of different impact distribution to policy makers. The use of this proxy is justified by the strong correlation identified by Morton et al. (2016) between LCVs and income. By focusing on vertical equity, this issue is brought to the attention of both scholars and decision makers. Based on Harrison and Shepherd (2014) the issue of low carbon vehicles (LCVs) uptake and the implications on predefined socio-economic groups is assessed through an empirical analysis. In this way, the overarching paper aim to operationalise different strands of research (Harrison and Shepherd, 2014; Thomopoulos and Grant-Muller, 2013; van Wee, 2011) and improve the practice of CBA is pursued.

Thus, the contribution of this paper lays in the application of selected ethical theories within transport CBA to revisit the issue of impact distribution when promoting low carbon policies which is apposite after the COP21 held in Paris. This paper starts off with an overview of common CBA criticisms then followed by a brief review of applicable ethical theories. By applying these theories in the context of the LCVs uptake in California, Section 4 offers evidence of the applicability of the suggested approach in different contexts. Hence, it contributes in the ongoing debate regarding the improvement of CBA in practice.

\section{Transport and ethics literature}

Transport can be both the cause and resolution of societal inequalities. The provision of transport for access to goods and services contrasts with potentially negative safety, environmental and social impacts, and as such can be subject to ethical debate (Mullen, 2012). There is a pertinent need at the moment to review and improve transport evaluation practices in developed countries amidst recession and budgetary constraints in Europe, the US and Japan, alongside the revitalised discussion about climate change globally (UNFCCC, 2015). Perhaps ethics and distributional implications have been neglected for a long time by academics and those involved in transport assessment, so recent publications aim at bridging this gap (Martens, 2015; Thomopoulos et al., 2009; van Wee, 2011) while addressing contemporary needs and the need to incorporate non-quantifiable impacts in the appraisal (Mackie and Preston, 1998). A similar research gap has been reported within a related sector, namely bioenergy, resulting in a need to reassess overall benefits of environmental policies and refocus attention to key issues 
surrounding such innovative policies including its social dimension (Levidow and Papaioannou, 2013). The novelty of such approaches lays in the fact that decision making in the transport sector has been dominated by engineers who perceive ethics as a sub-discipline of philosophy which is irrelevant to transport in their view (Bowen, 2012; van Wee, 2011). It is this identified gap which forms the rationale of this paper.

The complexity and abstraction of ethical theories may have rightly discouraged its inclusion in assessment frameworks to date, but theories such as the ones suggested by Rawls or Walzer may open new horizons to transport debates. Explaining such theories in more detail is out of the scope of this paper, yet both philosophy and ethics have a lot to offer to transport policy makers by challenging established practices (Harrison and Shepherd, 2014; Thomopoulos, 2013; van Wee, 2011). Attempts to operationalise ethical theories are not new as discussed in this section. However, attempts to operationalise theories such as Rawls' in such a detailed level have been rare to date.

On one hand, CBA remains the most commonly used assessment method in Europe (Odgaard et al., 2005) and other developed countries (Mackie and Worsley, 2013). On the other hand, the established view that welfare maximisation advocated by CBA should be the sole indicator used in transport interventions has been challenged, fostering approaches incorporating other methods such as multi-criteria analysis (MCA) (Annema et al., 2015; Guehnemann et al., 2012; Thomopoulos and Grant-Muller, 2013). Equally, Gardiner (2011) challenges utilitarianism which underpins CBA, followed by the severe criticism of CBA paralysis due to weaknesses of this method owed to the discount rate used and intergenerational equity. Others (Beukers et al., 2012; Mouter et al., 2013b, 2015; Pearce et al., 2006; Thomopoulos et al., 2007; Thomopoulos et al., 2009) have summarised the disadvantages of CBA, acknowledging though certain strengths of this method largely based on its appeal to policy makers. Nonetheless, acute views about CBA are not a new phenomenon since its critics have expressed their views at least since the 1970s (Turner, 1979).

Applying constructive criticism on CBA through the provision of useful suggestions has been a relatively new strand. This paper falls within this realm since it recognises certain virtues of CBA, but addresses its weakness regarding the disaggregation of impact distribution derived from welfare maximisation. A suitable way of achieving this is by introducing equity theories in transport assessment through CBA. In spite of the high number of authors who have developed and written about equity theories, only limited cases exist where such theories have been applied in the transport sector and fewer about LCVs.

Martens (2009) for example focuses on Walzer's (1983) spheres of justice stating that transport - conceived as accessibility by him - should have its own distributional sphere of justice since it has become a necessity in the 21 st century. Remarkably, he argues that neither mobility nor accessibility can be distributed based on the principle of equality. This view can be justified, but can be also overruled if equality is defined accordingly (e.g. equal annual cost of transport either in absolute terms or as an income proportion to use a LCV to commute to work - i.e., avoiding vehicle ownership). Neither Rawls' (1972) equity principles satisfy the strict conditions set out by Martens (2009). Yet, based on Walzer's spheres theory, it is important to identify according to which equity or distributive principle the 'transport good' should be allocated. This query is explored through the empirical analysis in Section 4.

Nevertheless, the adjusted Rawls (1972) principles operationalised by Khisty (1996) including the egalitarian principle appear to be appropriate for the analysis of this paper, 
thus are explained in Section 3 and utilised to derive the results discussed in Section 4. Such an approach warrants pursuing welfare maximisation both for the society overall and for certain social groups, addressing vertical equity concerns. The fact that it is uncommon for decision makers to share the same views about the applicable ethical theory ${ }^{1}$ in each case has obvious implications for the appraisal outcome since no common vision is shared. An increased interest about Rawls' theory could initiate new discussions among scholars and decision makers which could eventually lead in improving CBA practice.

\section{Methodology}

The methodology applied in this paper is based on a case study by Walther et al. (2010) which models the Californian low emission vehicles regulation to understand manufacturer response in an attempt to increase the market share of zero emission vehicles (ZEVs). This was extended by Harrison and Shepherd (2014) in an attempt to assess the impact of regulatory approaches on LCV purchases within a proposed ethical framework. Based on Harrison and Shepherd (2014) and Thomopoulos and Grant-Muller (2013), further analysis has been conducted here to adapt that case study, focusing on vehicle purchase costs instead of manufacturers' market shares to highlight short term distributional impacts and social implications of such environmental policies. The analysis in those papers includes both demand and supply side policy measures which constitute the backbone of the alternative policy scenarios developed. These scenarios are useful both for academics and decision makers because they provide the opportunity to test the impacts of alternative policies including the business as usual (BAU) scenario. Consequently, the focus in this paper is the deriving vertical equity implications for societal groups observed through a restricted CBA conducted from the perspective of a single LCV manufacturer operating in California for just over a decade (2009-2020).

It is worth mentioning here that although it is widely acknowledged (EC, 2013; IPCC, 2007; Stern, 2006, 2013; Rode et al., 2014) that LCVs should be adopted - either in the short-term or in the long-term - this adoption should not exacerbate inequalities between societal groups. The European Union has introduced a flexible legislation allowing manufacturers to assess their carbon emissions not per individual car but for their whole car fleet, set at $130 \mathrm{~g}$ of $\mathrm{CO}_{2} / \mathrm{km}$ for 2012-2015 and to $95 \mathrm{~g} \mathrm{CO}_{2} / \mathrm{km}$ from 2020 (EC, 2013). One of the motivations of this paper has been that although individual car use overall may decrease in the future as a result of environmental policies, certain already vulnerable societal groups - who may be more car-dependent - e.g. unemployed, elderly, disabled, should not be disadvantaged during the adjustment period. Rather this adjustment is expected to be facilitated through relevant government policies, maintaining or increasing vertical equity. Along the same lines, Harrison and Shepherd (2014) have demonstrated that the Regulation alternative policy scenario is the one with the highest potential success rate in reducing carbon emissions. Yet, this may favour those already most well off and users may bear more costs than government or industry, creating a problematic policy decision. Therefore this alternative scenario is used as the foundation of the core policy option in this paper. 
Nonetheless, it is essential to present here all the background information and assumptions of this analysis to offer a complete overview. The context of this analysis is California due to the advanced position of this state regarding the introduction of LCVs and the existence of previous analyses in that state. A further reason has been the sharper fall of family income in California compared to the rest of the US, particularly for those in the lower income quintiles, between 2007 and 2010 (Bohn and Schiff, 2011), which may have an adverse impact on household decisions in relation to LCV purchases since higher income levels have been strongly correlated with higher LCV purchases (Morton et al., 2016). Additionally, California is the only US state with four major cities with a median family income of less than $\$ 30,000$ available for new car purchases (Guillot, 2013). The time horizon (2009-2020) has been selected based on data availability. Further information and data about California used in this paper are presented in Table 1.

Table 1 Case study facts

\begin{tabular}{lc}
\hline Population (2010) & $37,253,956$ \\
Households (2007-2011) & $12,433,172$ \\
Population density per sq.mile (2010) & 239.1 \\
Average household size (2007-2011) & 2.91 \\
Median household income (2007-2011) & $\$ 61,632$ \\
Personal income (2009) & $\$ 41,034$ \\
Registered cars & $22,083,049$ \\
CVRA trucks & 440,751 \\
Non-CVRA trucks & $5,061,180$ \\
Miscellaneous vehicles & 126,705 \\
Total number of vehicles & $27,711,685$ \\
Vehicles per household & 2.17 \\
\hline \multicolumn{2}{c}{ Source CalStats (2012), CFED (2011) and US Census $(2013)$}
\end{tabular}

Source: CalStats (2012), CFED (2011) and US Census (2013)

Five household income quintiles ${ }^{2}$ (Table 2) have been used to create five societal groups (Q1-Q5 in Section 4.1) and review the impact distribution of costs and benefits of the uptake of LCVs in California. Each quintile has been designed to include $20 \%$ of the population based on CFED (2011) therefore societal groups include the same number of people but inevitably reflect diverse total incomes. Those who belong to the lower income quintile are less likely to own a car currently; therefore they are expected to benefit less (if at all) through any policies such as LCV purchase subsidies. Transport costs in California reflect the third largest budget share for the $25 \%$ of the lowest income households, whilst they comprise the second largest budget share after housing for all the rest of the households (PPIC, 2004b). Thus it is assumed that income can be used as a useful proxy in this paper. 
Table 2 Income quintiles in California

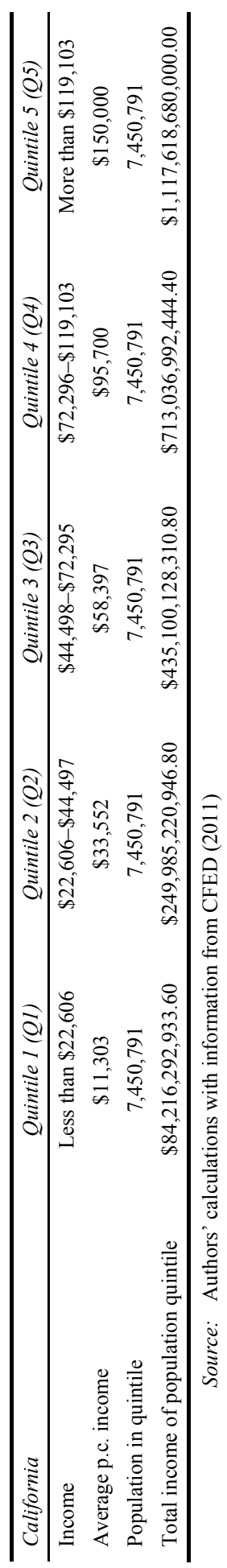


Having reviewed the societal grouping by Khisty (1996) where randomly defined income classes have been used, the approach in this paper is using the aforementioned income quintiles based on an egalitarian approach for each individual. By estimating the mean income for each quintile the total income for each quintile has been derived (Table 2). Another assumption used in this paper is that each quintile spends different income proportions for new vehicles (SBE, 2010) and will continue to spend similar income proportions for new LCVs in the future. As shown in Figure 1, spending on new vehicles increases from $3.1 \%$ of income for the lowest income quintile to $8.9 \%$ for the highest income quintile. Not surprisingly, income spent on used cars purchases decreases for the two highest income quintiles, since these users are able to afford new vehicles due to their higher earnings. However, these proportions are distinct from the income proportion spent on private vehicle expenditures which is $19 \%$ for low income quintiles and may reach $35 \%$ for very low income quintiles, while it averages $16 \%$ for all other income quintiles (PPIC, 2004a).

Figure 1 Household spending on new and used vehicles as a proportion of total California taxable spending by income quintile (see online version for colours)

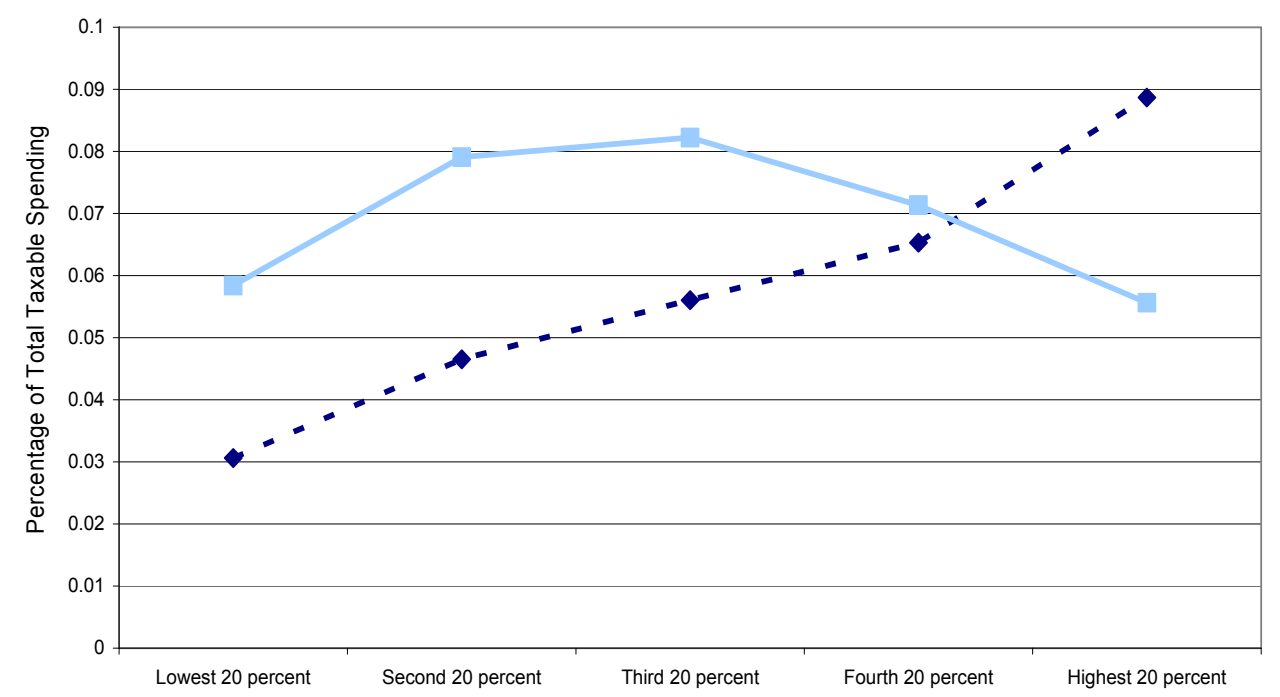

Household Income Quintile

Source: SBE (2010)

After establishing the background and assumptions of this analysis, it is also necessary to highlight the links with the contents of CBA. Since CBA revolves around welfare maximisation which in turn is intertwined with Kaldor-Hicks efficiency, this paper illustrates potential improvements about impact distribution elucidated through a CBA example. Due to the objectives of this paper, the focus here is on the distribution of vehicle purchase costs for users. Therefore, the User Purchase cost is distributed in each quintile based on alternative ethical theories. A range of theories have been selected based on the literature review and the prerequisite to be applicable in the current context of transport appraisal. These theories have been operationalised to five principles, namely: 
1 equal shares

2 egalitarian

3 maximum range between groups

4 minimum floor of impacts i.e. Rawls

5 equal proportions.

More details about their operationalisation are discussed in Sections 4 and 5.

In this way, this paper bridges the identified gap between Khisty (1996) and the need to introduce ethical theories in transport appraisal already discussed by scholars (Martens, 2009; Mouter, 2014; Thomopoulos, 2010; van Wee, 2011). Established inequality indicators (Gini, Theil, Atkinson) may not always produce similar results which is justified according to Sen (1973) due to the fact that each of these indicators is founded on alternative ethical judgements implying alternative approaches on the aggregation of information contained in the distribution. To complement the discussion about impact distribution with policy relevant findings, three policy options as described by Harrison and Shepherd (2014) are reviewed (Section 4.1):

1 subsidy

2 regulation

3 both policies.

To explore diverse impacts and minimise the intensification of vertical equity implications, these are contrasted with the BAU scenario.

\section{Results and discussion}

Based on the methodology described in the previous section, the results about LCVs are presented here followed by a discussion of the arising issues and the implications for improving the contents of CBA.

\subsection{Results}

Benefits in this analysis include reduced emissions (in MtGHG) which vary depending on the uptake and use of LCVs. Studies in Italy for example (Calabrese, 2015) have highlighted the potential benefits through government subsidies for the automotive industry. However, those studies have not focussed on distributional impacts and have excluded analysis about specific user groups. Analysis by others though (Table 3 ) has demonstrated two interesting findings related to this study. Crist (2012) has discussed how the introduction of government subsidies may significantly reduce the positive impacts of BEVs (used as a proxy of LCV in that case), which generates demand for a fruitful discussion about the cost and benefits of such policies. In addition, he points out the potential benefits for either a single manufacturer or a national sector focusing on BEVs manufacturing due to the anticipated benefits based on exports and international trade. The latter option is already being explored in France, which means that analyses similar to the one presented in this paper are contemporary and of high policy relevance. 
The system dynamics model described by Harrison and Shepherd (2014) has been used to simulate the overall costs and benefits of different policies. Due to the aim of this paper and the findings of Crist (2012), we have focussed on three alternative policy options, namely one which included only subsidies for LCVs, one which included only regulation for LCVs and one which included a combination of these two policies. Table 4 shows the costs of these policies as well as the emissions reduction impact which is the overall benefit in this analysis. Since the purpose of this paper has been to illustrate the method through this empirical analysis, we have solely focussed on costs. This is sensible since it has been assumed that all users are affected the same by GHGs.

Table 3 Lifetime fiscal and social revenues for a B class French ICE and BEV (€ per vehicle)

\begin{tabular}{lccccc}
\hline & \multicolumn{2}{c}{$I C E$} & & \multicolumn{2}{c}{$B E V$} \\
\cline { 2 - 3 } \cline { 5 - 6 } & Manufacture & Use & & Manufacture & Use \\
\hline Consumer expenditure & 14,600 & 17,650 & & 24,400 & 10,814 \\
Government revenue & & & & \\
VAT & 2,862 & 4,121 & & 4,782 & 2,119 \\
Fuel/Electricity Tax & & 3,375 & & & 420 \\
Production-related taxes & 1,002 & 1,031 & & 1,648 & 618 \\
Social security taxes & 10,594 & 12,837 & & 18,505 & 7,798 \\
Total revenue (no subsidy) & 14,457 & 21,364 & & 24,936 & 10,956 \\
(combined) & $(35,821)$ & & $(35,892)$ & 10,956 \\
Total revenue (ex subsidy) & 14,457 & 21,364 & & 18,956 & $(29,912)$ \\
(combined) & $(35,821)$ & & &
\end{tabular}

Notes: Assumptions: French tax rates, fuel and electricity prices, ICE fuel consumption $5 \mathrm{l} / 100 \mathrm{~km}$, BEV electricity consumption $18 \mathrm{kWh} / 100 \mathrm{~km}, 15,000 \mathrm{~km} / \mathrm{yr}$ both vehicles [for other assumptions, see: Leurent and Windisch (2012)].

Source: Crist (2012)

Table 4 Discounted costs (\$bn) of the three selected policies compared to baseline

\begin{tabular}{lcccccc}
\hline & $\begin{array}{c}\text { Government } \\
\text { costs }\end{array}$ & $\begin{array}{c}\text { User } \\
\text { purchase } \\
\text { costs }\end{array}$ & $\begin{array}{c}\text { User } \\
\text { running } \\
\text { costs }\end{array}$ & $\begin{array}{c}\text { Industry } \\
\text { costs }\end{array}$ & $\begin{array}{c}\text { Overall } \\
\text { costs }\end{array}$ & $\begin{array}{c}\text { Emissions } \\
\text { reduction } \\
\text { (Mt GHG) }\end{array}$ \\
\hline Subsidy & 1.18 & -0.95 & -0.18 & 0.13 & 0.18 & 0.97 \\
Regulation & 0.00 & 50.66 & -28.58 & -1.05 & 21.03 & 134.95 \\
Both policies & 1.35 & 49.38 & -28.68 & -0.93 & 21.11 & 135.57 \\
\hline
\end{tabular}

Source: Harrison and Shepherd (2014)

The overall costs column demonstrates the total cost of each policy which is the main value to be included in the CBA. This is then disaggregated to the key categories similarly to the benefit impact table (Nakamura, 2000) - which contain the government imposing the regulations and providing the subsidies, the Industry which includes a single manufacturer in this model - following Crist (2012) - and the users purchasing vehicles who face two types of costs i.e., purchase and running ones. Since there is a single manufacturer in this model for California (LCVs manufacturing is assumed to be a competitive market internationally) and the analysis focuses on a single market (regulated by one government), it is fair to assume that impact distribution matters more for 
individuals purchasing cars rather than for the two other categories of stakeholders i.e., the government and the single manufacturer. Therefore the remaining tables focus on impact distribution of user purchase costs among the five income quintiles in California which is the spatial region we focussed our analysis on.

When the government introduces subsidies to support the introduction of LCVs; this results in reduced purchase cost for users. Consequently, this policy has a user benefit ( $\$ 0.95 \mathrm{bn}$ ) in this analysis (the government bears a cost of $\$ 1.18$ bn - Table 4). In reality though this user benefit will benefit more the upper income quintiles as they will more likely be the ones purchasing the more expensive LCVs and thus receiving the larger benefit in absolute terms. Table 5 demonstrates the impacts for all users in each quintile initially and then for each individual user of each quintile. Five equity theories have been employed to operationalise the implications for each income group.

Table 5 Benefits distribution ( $\$ 0.95 \mathrm{bn}$ - Table 4 ) of user purchase costs among the five income quintile groups based on selected equity theories under the Subsidy Policy

\begin{tabular}{|c|c|c|c|c|c|}
\hline \multicolumn{6}{|c|}{ POLICY: SUBSIDY } \\
\hline & Equal shares & Egalitarian & $\begin{array}{c}\text { Maximum range } \\
\text { of } B \text { between } \\
\text { quintiles } \\
\text { (e.g., } \$ 100 \text { mil) }\end{array}$ & $\begin{array}{c}\text { Maximum } \\
\text { ceiling/Rawls } \\
\text { (e.g., } \$ 300 \text { mil) }\end{array}$ & $\begin{array}{c}\text { Equal } \\
\text { proportions }\end{array}$ \\
\hline \multicolumn{6}{|c|}{ Aggregate distribution } \\
\hline Q1 & $\$ 189,601,913$ & $\$ 407,572,024$ & $\$ 250,000,000$ & $\$ 300,000,000$ & $\$ 13,314,596$ \\
\hline Q2 & $\$ 189,601,913$ & $\$ 260,160,119$ & $\$ 200,000,000$ & $\$ 250,000,000$ & $\$ 61,196,382$ \\
\hline Q3 & $\$ 189,601,913$ & $\$ 158,723,214$ & $\$ 180,000,000$ & $\$ 200,000,000$ & $\$ 126,483,607$ \\
\hline Q4 & $\$ 189,601,913$ & $\$ 90,855,357$ & $\$ 170,000,000$ & $\$ 150,000,000$ & $\$ 240,008,252$ \\
\hline Q5 & $\$ 189,601,913$ & $\$ 30,650,000$ & $\$ 150,000,000$ & $\$ 48,000,000$ & $\$ 507,287,119$ \\
\hline \multicolumn{6}{|c|}{ Per capita distribution } \\
\hline Q1 p.c. & $\$ 25$ & $\$ 55$ & $\$ 34$ & $\$ 40$ & $\$ 2$ \\
\hline Q2 p.c. & $\$ 25$ & $\$ 35$ & $\$ 27$ & $\$ 34$ & $\$ 8$ \\
\hline Q3 p.c. & $\$ 25$ & $\$ 21$ & $\$ 24$ & $\$ 27$ & $\$ 17$ \\
\hline Q4 p.c. & $\$ 25$ & $\$ 12$ & $\$ 23$ & $\$ 20$ & $\$ 32$ \\
\hline Q5 p.c. & $\$ 25$ & $\$ 4$ & $\$ 20$ & $\$ 6$ & $\$ 68$ \\
\hline
\end{tabular}

Notes: Total benefit for all users in the quintile, per capita benefit for users in quintile.

Q1 has the lowest income, whereas Q5 has the highest income

According to the equal shares theory, all income groups share the subsidy policy benefits equally $(\$ 189,601,913)$. The egalitarian approach advocates that the end situation should bring all users to a more equal situation, therefore lower incomes benefit by higher subsidies to allow them to purchase LCVs and/or purchase larger LCVs depending on their household situation. Based on the maximum range of benefits approach, the income quintile receiving the highest benefits should not receive an absolute benefit over a predefined maximum range compared to the benefits received by other quintiles (e.g., \$100 mil). Similarly, utilising Rawlsian theory, a maximum ceiling may be predefined not allowing any given income quintile to receive more benefits than this predefined threshold (e.g., $\$ 300$ mil). With such an approach it is safeguarded that disadvantaged groups will improve their absolute situation, while advantaged ones will 
maintain their relatively advantageous position. On the other hand, the equal proportions approach is based on the distribution of benefits based on the income proportion spent by each quintile to purchase new cars (SBE, 2010). The fact that higher income individuals will receive more subsidies may appear as a paradox, but this will be discussed in the next section.

Moving on to the second policy, Table 6 shows the impact distribution according to the regulation policy. Naturally, this policy has no financial cost for the government, whereas it introduces considerable costs for users intensified by the fact that manufacturers are able to pass regulation costs to end users (see Table 4 and Table 6). Therefore, costs are considerably higher compared to the benefits in the previous policy option and reach $\$ 27$ bn for the highest income quintile (Q5) in the equal proportions approach (Table 6). A progressive cost distribution has been applied based on the Egalitarian theory, where the lowest income quintile (Q1) will have to contribute $\$ 1.5 \mathrm{bn}$, whilst Q5 will have to contribute almost $\$ 22$ bn. A $\$ 5$ bn maximum range threshold has been set for the respective principle, whilst a minimum range of $\$ 1.2$ bn has been set for the Rawlsian approach based on an almost $50 \%$ contribution of the average car purchase expenses of the lowest income group. It is noteworthy that the equal proportions approach results in a lower contribution by the lowest income groups in this policy option compared with the subsidy policy where benefits were distributed instead of costs.

Table 6 Cost distribution ( $\$ 50.66$ bn - Table 4$)$ of user purchase costs among the five income quintile groups based on selected equity theories under the Regulation Policy

\begin{tabular}{|c|c|c|c|c|c|}
\hline \multicolumn{6}{|c|}{ POLICY: REGULATION } \\
\hline & Equal shares & Egalitarian & $\begin{array}{c}\text { Maximum range } \\
\text { of } C \text { between } \\
\text { quintiles } \\
\text { (e.g., } \$ 5 \text { bn) }\end{array}$ & $\begin{array}{l}\text { Minimum } \\
\text { floor/Rawls } \\
(\$ 1.2 \mathrm{bn})\end{array}$ & $\begin{array}{c}\text { Equal } \\
\text { proportions }\end{array}$ \\
\hline \multicolumn{6}{|c|}{ Aggregate distribution } \\
\hline Q1 & $\$ 10,132,117,830$ & $\$ 1,586,000,000$ & $\$ 8,000,000,000$ & $\$ 1,227,031,388$ & $\$ 711,417,135$ \\
\hline Q2 & $\$ 10,132,117,830$ & $\$ 4,861,428,571$ & $\$ 9,000,000,000$ & $\$ 5,519,673,679$ & $\$ 3,269,806,690$ \\
\hline Q3 & $\$ 10,132,117,830$ & $\$ 8,492,857,143$ & $\$ 10,000,000,000$ & $\$ 9,920,282,925$ & $\$ 6,758,192,743$ \\
\hline Q4 & $\$ 10,132,117,830$ & $\$ 13,920,476,190$ & $\$ 11,000,000,000$ & $\$ 14,118,132,450$ & $\$ 12,823,970,309$ \\
\hline Q5 & $\$ 10,132,117,830$ & $\$ 21,808,095,238$ & $\$ 13,000,000,000$ & $\$ 19,893,612,504$ & $\$ 27,105,047,037$ \\
\hline \multicolumn{6}{|c|}{ Per capita distribution } \\
\hline Q1 p.c. & $\$ 1,360$ & $\$ 213$ & $\$ 1,074$ & $\$ 165$ & $\$ 95$ \\
\hline Q2 p.c. & $\$ 1,360$ & $\$ 652$ & $\$ 1,208$ & $\$ 741$ & $\$ 439$ \\
\hline Q3 p.c. & $\$ 1,360$ & $\$ 1,140$ & $\$ 1,342$ & $\$ 1,331$ & $\$ 907$ \\
\hline Q4 p.c. & $\$ 1,360$ & $\$ 1,868$ & $\$ 1,476$ & $\$ 1,895$ & $\$ 1,721$ \\
\hline Q5 p.c. & $\$ 1,360$ & $\$ 2,927$ & $\$ 1,745$ & $\$ 2,670$ & $\$ 3,638$ \\
\hline
\end{tabular}

Notes: Total cost for all users in the quintile, per capita benefit for users in quintile.

Q1 has the lowest income, whereas Q5 has the highest income.

Yet, the third and most plausible policy option is based on a combination of both policies. As explained in Section 3, an equal contribution of the subsidy and regulation policy options has been incorporated in the model used for this analysis and the results are 
shown in Table 7. The results are equivalent to the regulation policy reflecting the slightly lower user cost due to the positive impact of the inclusion of the subsidy policy.

Table 7 Cost distribution ( $\$ 49.38$ bn - Table 4) of user purchase costs among the five income quintile groups based on selected equity theories under both (Subsidy and Regulation) policies

\begin{tabular}{lccccc}
\hline BOTH POLICIES & Equal shares & Egalitarian & $\begin{array}{c}\text { Maximum range } \\
\text { of C between } \\
\text { quintiles } \\
(\text { e.g., } \$ 5 \text { bn })\end{array}$ & $\begin{array}{c}\text { Minimum } \\
\text { floor/Rawls } \\
(\$ 1 \text { bn })\end{array}$ & $\begin{array}{c}\text { Equal } \\
\text { proportions }\end{array}$ \\
\hline Aggregate distribution & & & & \\
\hline Q1 & $\$ 9,875,267,968$ & $\$ 1,596,378,920$ & $\$ 7,000,000,000$ & $\$ 1,000,000,000$ & $\$ 693,272,734$ \\
Q2 & $\$ 9,875,267,968$ & $\$ 4,732,123,228$ & $\$ 9,000,000,000$ & $\$ 4,445,000,000$ & $\$ 3,186,411,620$ \\
Q3 & $\$ 9,875,267,968$ & $\$ 8,266,962,265$ & $\$ 10,000,000,000$ & $\$ 9,920,282,925$ & $\$ 6,585,827,827$ \\
Q4 & $\$ 9,875,267,968$ & $\$ 13,550,216,310$ & $\$ 11,000,000,000$ & $\$ 14,118,132,450$ & $\$ 12,496,900,241$ \\
Q5 & $\$ 9,875,267,968$ & $\$ 21,228,038,736$ & $\$ 12,000,000,000$ & $\$ 19,893,612,504$ & $\$ 26,413,744,002$ \\
\hline Per capita distribution & & & & \\
\hline Q1 p.c. & $\$ 1,325.40$ & $\$ 214.26$ & $\$ 939.50$ & $\$ 134.21$ & $\$ 93.05$ \\
Q2 p.c. & $\$ 1,325.40$ & $\$ 635.12$ & $\$ 1,207.93$ & $\$ 596.58$ & $\$ 427.66$ \\
Q3 p.c. & $\$ 1,325.40$ & $\$ 1,109.54$ & $\$ 1,342.14$ & $\$ 1,331.44$ & $\$ 883.91$ \\
Q4 p.c. & $\$ 1,325.40$ & $\$ 1,818.63$ & $\$ 1,476.35$ & $\$ 1,894.85$ & $\$ 1,677.26$ \\
Q5 p.c. & $\$ 1,325.40$ & $\$ 2,849.10$ & $\$ 1,610.57$ & $\$ 2,670.00$ & $\$ 3,545.09$ \\
\hline
\end{tabular}

Notes: Total cost for all users in the quintile, per capita benefit for users in quintile.

Q1 has the lowest income, whereas Q5 has the highest income.

An overview of the total contribution of each income quintile according to the five selected equity theories is presented in Figure 2. As anticipated the quintiles with the higher income (Q4 and Q5) contribute more than the quintiles with the lower income (Q1-Q3), particularly when the egalitarian, Rawlsian and equal proportions theories are applied (Figure 2). In addition to the results presented through Tables 5-7, some further findings come out of the analysis of the system dynamics model. Vehicle size (XS, S, M, L) appears to play a key role as anticipated and this is discussed in the subsequent section. This is justified since the introduction of very small (XS) LCVs results in decreased demand for all other car sizes (Walther et al., 2010). Remarkably though, findings suggest that purchase costs of large (L) vehicles - cICEV - have increased at a lower rate compared to small (S) vehicles, $28 \%$ to $13 \%$ respectively (Harrison and Shepherd, 2014). The latter highlights the existence of certain fixed costs for the manufacturing of any size of LCVs which raises vertical equity concerns. Moreover, the introduction of penalties about emission reduction and LCV technologies appear to be the most effective policy measures which could avoid the transfer of costs from manufacturers to those purchasing cars. 
Figure 2 Overview of each income quintile contribution based on the five equity theories (see online version for colours)

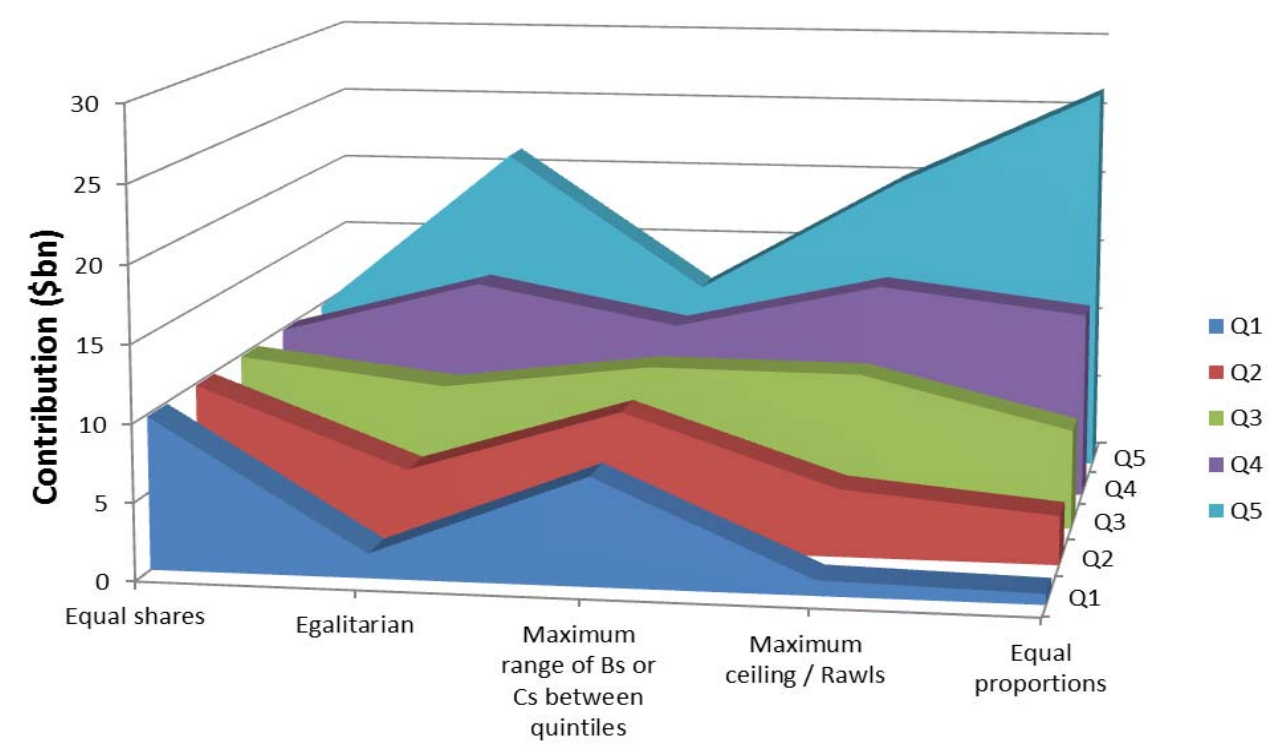

\section{Both policies}

\subsection{Discussion}

A series of issues have arisen through the empirical analysis of the LCVs uptake in California. First we discuss some issues based on the findings and then some wider methodological issues relevant to the wider aims of this paper.

As argued by Harrison and Shepherd (2014), vehicle size may be used as an income proxy for such a disaggregation, using the four vehicle sizes (XS, S, M, L) as defined by Walther et al. (2010). If such a proxy is used, it can be assumed that lower income households purchase smaller sized vehicles whereas higher income households purchase larger vehicles. This may correspond for California but would need to be reviewed for other developed areas e.g., Europe, where those in higher income quintiles sometimes purchase small cars. Generally speaking though, lower income households have limited (if any) income proportion to spend on purchasing a car. Table 8 reviews the cost increase impacts between 2009 and 2020 for each vehicle size. If this proxy is used, then these vehicle purchase cost increases can be linked with the income quintiles and the impact distribution analysis which preceded in Section 4.1. Although the price differentials remain fairly constant, the simulation of different policy scenarios has allowed the identification of uneven cost burdens for those purchasing small vehicles (S) when ICE vehicles are gradually forced out of the market to reduce the overall GHGs impact. This may have an adverse effect for those on lower incomes (e.g., Q1 or Q2 in Section 4.1) which could be acknowledged in the decision making process when reviewing policy options, since the increase of $28 \%$ is more than double the increase for large vehicles. 
Table 8 Average LCV purchase cost for various car sizes

\begin{tabular}{lcccc}
\hline Car size & $\begin{array}{c}\text { Start year } \\
(2009)\end{array}$ & $\begin{array}{c}\text { Fixed baseline } \\
(2020)\end{array}$ & $\begin{array}{c}\text { Both policies } \\
(2020)\end{array}$ & $\begin{array}{c}\text { \% difference in } \\
\text { 2020 between } \\
\text { policies }\end{array}$ \\
\hline $\mathrm{XS}$ & $\mathrm{n} / \mathrm{a}$ & 13,432 & 15,048 & $12 \%$ \\
$\mathrm{~S}$ & 12,799 & 16,172 & 20,698 & $28 \%$ \\
$\mathrm{M}$ & 17,749 & 21,683 & 25,340 & $15 \%$ \\
$\mathrm{~L}$ & 27,649 & 30,365 & 34,413 & $13 \%$ \\
\hline
\end{tabular}

Notes: XS: extra small, S: small, M: medium, L: large.

Source: Harrison and Shepherd (2014)

Although Table 8 shows some interesting findings, it would have been useful to have accurate facts about the mix of vehicle size for each income quintile (or other societal grouping) to avoid errors in planning assumptions as well as in the definition of the BAU scenario and the do minimum scenario. The latter could act as a major improvement in the accuracy of such analyses as Mackie and Preston (1998) have pointed out and could be the focus of future research. Furthermore, the introduction of policies such as the promotion of LCVs impacts disproportionately certain groups of users who often do not have reasonable alternatives. For example, those who have no access at home charging facilities - for electric vehicles - or have high travel commitments will be disadvantaged. Imposing regulatory penalties would achieve the greatest GHG emission reductions, but would also increase purchase costs and change market shares, impacting disproportionately certain societal groups due to diverse income levels and car use reliance. When considering those who are most vulnerable to purchase cost changes, non-car owners may have little reliance on cars at this point in time, but their opportunity of purchasing a car (if needed) in the future is further prevented by the increased costs, deteriorating their position relatively. Similar impacts may occur for the less affluent societal groups and those who may already own an ICE car.

This point brings up one of the core arguments of this paper which is the operationalisation of selected ethical theories to improve the contents of CBA. These are presented in a neutral way and without the authors' intention of arguing in favour of any specific approach. Moreover, the objective is to highlight the advantage of carrying out a pluralist assessment. Five different approaches have been operationalised and presented in Section 4.1, so here we review particular points to generate discussion and provide some practical suggestions. In the definition of the maximum range (or ceiling) for example, there is an inherent issue of subjectivity since this can be an arbitrary decision. Yet in practice this can either be linked with an absolute sum based on a predefined amount which higher income quintiles can be asked to contribute or linked with the proportional difference between the average income of the lowest and highest income quintiles. The strong correlation identified (Morton et al., 2016) between higher income and LCVs could justify such practice.

On the other hand, consistent use of such approaches may also create paradoxes as was the case in the equal proportions approach where higher incomes received more benefits (Table 5). Inversely, if there are net costs (the reduction of GHGs is one such case, although it is acknowledged that most CBAs of funded projects have net benefits) lower income quintiles bear lower costs. Reviewing the rest of the ethical principles operationalised in Section 4.1, the equal shares is probably the easiest to implement since 
all costs or benefits are distributed equally among the societal groups. For the egalitarian principle, two factors have been considered in this paper:

1 the average income of each quintile spent on new car purchases

2 the proportional relationship between the lowest income quintile group (which has been used as the basis) with the other quintile income groups.

A different point which needs to be stressed though is that in the future state revenues may decrease due to lower fuel tax revenues (Shepherd et al., 2012) as experienced in 2015 due to lower oil prices globally, but they may also increase through the need to renew car fleets more often due to LCVs' maintenance issues which have implications for user running costs. Therefore, further analysis of interactions and dynamics is required at diverse spatial and societal levels, specifically for government impacts of LCV policies. The use of system dynamics as suggested in this paper may facilitate such analyses further.

\section{Conclusions and future research}

Overall, it can be said that despite the inherent difficulties and inevitable subjectivity when attempting to operationalise ethical theories in transport appraisal, this can be achieved with promising results as demonstrated. As Aldred (2012) put it: "if a large cut in emissions is to be made by society overall, everyone should 'do their bit' by making a particular kind of sacrifice rather than paying others to do it instead". Thus, having applied selected ethical theories in the appraisal of policies for the uptake of LCVs in California, this paper has illustrated the potential improvements into CBA practice which can increase the decision makers' overview of impact distribution (Figure 2) while continuing to benefit by the merits of CBA. Findings should be reviewed along with the urge to utilise multiple methods forming an integrated appraisal framework which incorporates CBA, modelling and ethical components since those can work in parallel and complement each other. It appears that system dynamics modelling represents a promising approach for addressing deeply uncertain dynamically complex societal challenges (Kwakkel and Pruyt, 2013). In summary, findings of this paper build up on previous findings (Harrison, 2013a, 2013b; Thomopoulos and Grant-Muller, 2013) and suggest that the stages to follow should be:

- to identify relevant ethical and equity issues

- to agree on the ethical theory to be used

- to develop a model addressing these issues

- to formulate mitigation policies acknowledging that the model should not be used in isolation but in combination with other methods such as CBA.

Such an approach can lead to more informed decision making, noting though that any method should not be used as a crystal ball replacing policy makers. The latter corresponds with the findings of Mouter et al. (2013a) where the role of CBA in The Netherlands has been reviewed to conclude that CBA has a crucial role to play in policy making, yet it cannot substitute policy makers. Common practice and guidelines exist for selected developed countries (Mackie and Worsley, 2013); nevertheless these guidelines 
may provide best practice examples whilst accommodating the needs of developing countries (Dimitriou and Gakenheimer, 2011) by allowing customisation of the appraisal to their respective context. The latter is founded on the grounds that there may have to be diversions based on different market prices, discount rates or time horizons. These findings are of particular interest for automotive manufacturers and policy makers following the COP21 agreement in Paris (UNFCCC, 2015).

Overall, many may argue that policy makers will not find it easy to accommodate multiple concerns including ethical ones in their decisions (Wolff, 2011) despite it has been demonstrated that the assessment tool selection introduces both practical and ethical implications (Gasparatos and Scolobig, 2012). It becomes nonetheless evident through such analyses that the ethical element will gain increased importance in future environmental policy making as well as in academic debates supporting decision making and evaluation (Ersdal and Aven, 2008; Stern, 2013).

\section{Acknowledgements}

The authors are thankful to the anonymous reviewers as well as the participants of the workshop 'Improving CBA for spatial infrastructure plans: contents and process' held at the University of Amsterdam (11 September 2013) and also to the participants of the RSA Research Network Seminar on Low Carbon Mobility - Policy Approaches and Regional Development in Mature and Emerging Economies held at Jagiellonian University (8-9 October 2015) for comments on earlier versions of this paper.

\section{References}

Aldred, J. (2012) 'The ethics of emissions trading', New Political Economy, Vol. 17, No. 3, pp.339-360.

Annema, J.A., Mouter, N. and Razaei, J. (2015) 'Cost-benefit analysis (CBA), or multi-criteria decision-making (MCDM) or both: politicians' perspective in transport policy appraisal', Transportation Research Procedia, Vol. 10, pp.788-797.

Beukers, E., Bertolini, L. and Te Brommelstoet, M. (2012) 'Why cost benefit analysis is perceived as a problematic tool for assessment of transport plans: a process perspective', Transportation Research Part A: Policy and Practice, Vol. 46, No. 1, pp.68-78.

Bohn, S. and Schiff, E. (2011) The Great Recession and Distribution of Income in California, Public Policy Institute of California, San Francisco.

Bowen, R. (2012) 'Ethics and the engineer: professional codes and the rule of St. Benedict', Studies in Christian Ethics, Vol. 25, No. 3, pp.277-294.

Calabrese, G. (2015) 'Outlining policy responses to stimulate automotive car demand by environmental impact reduction', Journal of Environmental Planning and Management, Vol. 58, No. 1, pp.55-68.

CalStats (2012) Registered Vehicle Statistics, State of California, Department of Motor Vehicles [online] http://dmv.ca.gov/about/profile/official.pdf (accessed 10 July 2013).

CFED (2011) Assets and Opportunity Scorecard - California Facts Source [online] http://scorecard.assetsandopportunity.org/2013/measure/state-income-quintiles-acs (accessed 16 August 2013).

Crist, P. (2012) Electric Vehicles Revisited - Costs, Subsidies and Prospects, OECD - ITF Discussion Paper 2012-03, Paris. 
Dimitriou, H. and Gakenheimer, R. (2011) Urban Transport in the Developing World: A Handbook of Policy and Practice, Edward Elgar, Thousand Oaks.

EC (2013) Regulation No 443/2009 of the European Parliament and of the Council of 23/4/2009: Setting Emission Performance Standards for New Passenger Cars as Part of the Community's Integrated Approach to Reduce $\mathrm{CO}_{2}$ Emissions from Light Duty Vehicles, Amended by Commission Regulation (EU) No397/2013, Official Journal L120, p.4, 1 May.

Eliasson, J. and Lundberg, M. (2012) 'Do cost-benefit analyses influence transport investment decisions? Experiences from the Swedish transport investment plan 2010-21', Transport Reviews, Vol. 32, No. 1, pp.29-48.

Ersdal, A. (2008) 'Risk informed decision-making and its ethical basis', Reliability Engineering \& System Safety, Vol. 93, No. 2, pp.197-205.

Folland, S., Goodman, A.C. and Stano, M. (2007) The Economics of Health and Health Care, Vol. 6, Pearson Prentice Hall, New Jersey.

Gardiner, S. (2011) A Perfect Moral Storm: The Ethical Tragedy of Climate Change (Environmental Ethics and Science Policy), Oxford University Press, New York.

Gasparatos, A. and Scolobig, A. (2012) 'Choosing the most appropriate sustainability assessment tool', Ecological Economics, Vol. 80, pp.1-7 [online] http://oneplanetthriving.com/wpcontent/uploads/2013/01/ChoosingSustainabilityAssessTool_GasparatosAndScolobig_2012.p df.

Ghermandy, A., Ding, H. and Nunes, P. (2013) 'The social dimension of biodiversity policy in the European Union: valuing the benefits to vulnerable communities', Environmental Science and Policy, Vol. 33, pp.196-208 [online] https://www.researchgate.net/publication/247158164 The_social_dimension_of_biodiversity_policy_in_the_European_Union_Valuing_the_benefit S_to_vulnerable_communities.

Guehnemann, A., Laird, J. and Pearman, A. (2012) 'Combining cost-benefit and multi-criteria analysis to prioritise a national road infrastructure programme', Transport Policy, Vol. 23, pp.15-24 [online] http://www.sciencedirect.com/science/article/pii/S0967070X12000753.

Guillot, C. (2013) Car Prices Outpace Median Income in All But One Major City [online] http://www.interest.com/auto/news/car-prices-outpace-median-income/ (accessed 10 July 2013).

Harrison, G. (2013a) New Fuels, New Rules? Modelling Policies for the Uptake of Low Carbon Vehicles Within an Ethical Framework, Integrated Masters and $\mathrm{PhD}$ in Low Carbon Technologies, University of Leeds.

Harrison, G. (2013b) 'New fuels, new rules? Development of inequality impact indicators of alternative fuel vehicle policies', 13th WCTR, Rio de Janeiro, Brazil, 15-18 July.

Harrison, G. and Shepherd, S. (2014) 'An interdisciplinary study to explore impacts from policies for the introduction of low carbon', Transportation Planning and Technology, Vol. 37, No. 1, pp.98-117.

IPCC (2007) IPCC Fourth Assessment Report: Climate Change 2007 (AR4), Intergovernmental Panel on Climate Change, Cambridge and New York, USA.

ITF (2011) Improving the Practice of Cost Benefit Analysis in Transport: Summary and Conclusions, JTRC Roundtable, 20-21 October 2010, Queretaro, Mexico.

Khisty, J. (1996) 'Operationalizing concepts of equity for public project investments', Transportation Research Record, Vol. 1559, No. 1, pp.94-99.

Kwakkel, J. and Pruyt, E. (2013) 'Using system dynamics for grand challenges: the ESDMA approach', Systems Research and Behavioral Science, Vol. 32, No. 3, pp.358-375, doi: $10.1002 /$ sres.2225.

Leurent, F. and Windisch, E. (2012) 'Benefits and costs of electric vehicles for the public finances: integrated valuation model and application to France', ATEC ITS Conference France 2012: Smart Mobility: From Research to Practice [online] https://hal.archives-ouvertes.fr/hal00680987/document. 
Levidow, L. and Papaioannou, T. (2013) 'State imaginaries of the public good: shaping UK innovation priorities for bioenergy', Environmental Science and Policy, Vol. 30, pp.36-49 [online] http://www.sciencedirect.com/science/article/pii/S1462901112001797.

Mackie, P. (2011) Cost Benefit Analysis in Transport, OECD-Discussion Papers 16, ITF-JTRC Roundtable, Mexico.

Mackie, P. and Preston, J. (1998) 'Twenty-one sources of error and bias in transport project appraisal', Transport Policy, Vol. 5, No. 1, pp.1-7.

Mackie, P. and Worsley, T. (2013) International Comparisons of Transport Appraisal Practice: Overview Report, Under DfT Contract PPRO 04/03/31, Institute for Transport Studies, University of Leeds, Leeds, UK.

Marsden, G. and Hess, S. (2011) 'The scope and potential impacts of the adoption of electric vehicles in UK surface transport', in Jamasb, T. and Pollitt, M. (Eds.): The Future of Electricity Demand: Customers, Citizens and Loads, pp.212-230, Cambridge University Press, Cambridge.

Martens, K. (2009) 'Justice in transport - applying Walzer's spheres of justice to the transport sector', 88th Annual Transportation Research Board Meeting, Washington, DC.

Martens, K. (2015) Access for All: A New Paradigm for Transportation Planning Based on Principles of Social Justice, Taylor and Francis, London.

Morton, C., Anable, J., Yeboah, G. and Cottrill, C. (2016) 'Exploring the spatial pattern of demand in the early market for electric vehicles: evidence from the United Kingdom', Paper presented at $A A G 2016$ Annual Meeting, San Francisco, CA.

Mouter, N. (2014) Cost-Benefit Analysis in Practice, PhD thesis, Delft University of Technology, The Netherlands.

Mouter, N., Annema, J-A. and van Wee, B. (2013a) 'Attitudes towards the role of cost-benefit analysis in the decision-making process for spatial-infrastructure projects: a Dutch case study', Transportation Research Part A, Vol. 58, No. C, pp.1-14.

Mouter, N., Annema, J-A. and van Wee, B. (2013b) 'Ranking the substantive problems in the Dutch cost-benefit analysis practice', Transportation Research Part A, March, Vol. 49, pp.241-255 [online] http://www.sciencedirect.com/science/journal/09658564/49/supp/C.

Mouter, N., Annema, J-A. and van Wee, B. (2015) 'Managing the insolvable limitations of cost-benefit analysis: results of an interview based study', Transportation, Vol. 42, No. 2, pp.277-302.

Mullen, C. (2012) Mobility (Transport). Encyclopaedia of Applied Ethics, 2nd ed., in Chadwick, R. (Ed.), Elsevier Limited, London (UK), Waltham and San Diego (USA).

Nakamura, H. (2000) 'The economic evaluation of transport infrastructure: needs for international comparisons', Transport Policy, Vol. 7, No. 1, pp.3-6.

Odgaard, T., Kelly, C. and Laird, J. (2005) Current Practice in Project Appraisal in Europe Analysis of Country Reports, FP6-HEATCO Contract No. FP6-2002-SSP-1/502481 Deliverable 1 [online] http://heatco.ier.uni-stuttgart.de/hd1 final.pdf (accessed 26 May 2013).

Oxley, T., Elshkaki, A., Kwiatkowski, L., Castillo, A., Scarbrough, T. and ApSimon, H. (2012) 'Pollution abatement from road transport: cross-sectoral implications, climate co-benefits and behavioural change', Environmental Science and Policy, May-June, Vols. 19-20, pp.16-32.

Pearce, D., Atkinson, G. and Mourato, S. (2006) Cost-Benefit Analysis and the Environment: Recent Developments, OECD, Paris.

Podhora, A., Helming, K., Adenauer, L., Heckelei, T., Kautto, P., Reidsma, P., Rennings, K., Turnpenny, J. and Jansen, J. (2013) 'The policy-relevancy of impact assessment tools: evaluating nine years of European research funding', Environmental Science and Policy, Vol. 31, pp.85-95, DOI: 10.1016/j.envsci.2013.03.002.

PPIC (2004a) How Much do California's Low Income Households Spend on Transportation, Research Brief, Public Policy Institute of California [online] http:/www.ppic.org/contents/ pubs/rb/RB_704LRRB.pdf (accessed 10 July 2013). 
PPIC (2004b) Transportation Spending by Low-Income California Households: Lessons for the San Francisco Bay Area, by Rice, L. [online] http://www.ppic.org/contents/pubs/ report/R_704LRR.pdf (accessed 10 July 2013).

Rawls, J. (1972) Theory of Justice, Oxford University Press, Oxford.

Rode, P., Floater, G., Thomopoulos, N., Schwinger, P., Mahendra, A. and Fang, W. (2014) Accessibility in Cities: Transport and Urban Form, New Climate Economy Cities Paper 3, LSE Cities, London School of Economics and Political Science.

Roeser, S. (2006) 'The role of emotions in judging the moral acceptability of risks', Safety Science, Vol. 44, No. 8, pp.689-700.

Roeser, S. (2012) 'Emotional engineers: toward morally responsible design', Science and Engineering Ethics, Vol. 18, No. 1, pp.103-115.

SBE (2010) Taxable Spending and Income, Economic Perspective, Publication 329, Discussion of Recent Economic Developments, Vol. 16, No. 3 [online] http://www.boe.ca.gov/news/ pdf/epaugust10.pdf (accessed 10 July 2013).

Sen, A. (1973) On Economic Inequality, Oxford University Press, Oxford.

Shepherd, S., Bonsall, P. and Harrison, G. (2012) 'Factors affecting future demand for electric vehicles: a model based study', Transport Policy, March, Vol. 20, pp.62-74.

Stern, N. (2006) Stern Review on the Economics of Climate Change, HM Treasury, London.

Stern, N. (2013) Ethics, Equity and the Economics of Climate Change, Centre for Climate Change Economics and Policy, Working Paper No.97a, Grantham Research Institute on Climate Change and the Environment, Working Paper No.84a, November.

Thomopoulos, N. (2010) Incorporating Equity in the Assessment of Large Transport Infrastructure Projects, $\mathrm{PhD}$ thesis, Institute for Transport Studies, University of Leeds.

Thomopoulos, N. (2013) 'Transport and ethics: ethics and the evaluation of transport policies and projects, book review', Transport Reviews, Vol. 33, No. 4, pp.497-498.

Thomopoulos, N. and Grant-Muller, S. (2013) 'Incorporating equity as part of the wider impacts in transport infrastructure assessment: an application of the SUMINI approach', Transportation, Vol. 40, No. 2, pp.315-345.

Thomopoulos, N., Givoni, M. and Rietveld, P. (2015) ICT for Transport: Opportunities and Threats, Edward Elgar, Cheltenham.

Thomopoulos, N., Grant-Muller, S. and Tight, M. (2007) 'Can equity be included in appraisal of large transport infrastructure projects? A review of past European practice and principles', Proceedings of the Network on European Communications and Transport Activities (NECTAR) Bi-Annual Conference, Porto, Portugal, May.

Thomopoulos, N., Grant-Muller, S. and Tight, M. (2009) 'Incorporating equity considerations in transport infrastructure evaluation: current practice and a proposed methodology', Evaluation and Program Planning, Vol. 32, No. 4, pp.351-359.

Thornton, A., Evans, L., Bunt, K., Simon, A., King, S. and Webster, T. (2011) Climate Change and Transport Choices Segmentation Model, Annex to the Main Report, Department for Transport.

Turner, K. (2007) 'Limits to CBA in UK and European environmental policy: retrospects and future prospects', Environmental and Resource Economics, Vol. 37, No. 1, pp.253-269.

Turner, R.K. (1979) 'Cost-benefit analysis - a critique', OMEGA The International Journal of Management Science, Vol. 7, No. 5, pp.414-419.

UNFCCC (2015) Historic Paris Agreement on Climate Change: 195 Nations Set Path to Keep Temperature Rise Well Below 2 Degrees Celsius, United Nations Climate Change Newsroom, 12 December [online] http://newsroom.unfecc.int/unfccc-newsroom/finale-cop21/ (accessed 18 December 2015).

US Census (2013) State and County QuickFacts [online] http://quickfacts.census.gov/qfd/states/06000.html (accessed 10 July 2013). 
van Wee, B. (2011) 'Transport and ethics: ethics and the evaluation of transport policies and projects', in Transport Economics, Management \& Policy Series, Edward Elgar, Cheltenham, UK.

van Wee, B. (2012) 'How suitable is CBA for the ex-ante evaluation of transport projects and policies? A discussion from the perspective of ethics', Transport Policy, Vol. 19, No. 1, pp.1-7.

Vickerman, R. (2007) 'Cost-benefit analysis and large scale infrastructure projects: state of the art and challenges', Environment and Planning B, Vol. 34, No. 4, pp.598-610.

Walther, G., Wansart, J., Kieckhaefer, K., Schnieder, E. and Spengler, T. (2010) 'Impact assessment in the automotive industry: mandatory market introduction of alternative powertrain technologies', System Dynamics Review, Vol. 26, No. 3, pp.239-261.

Walzer, M. (1983) Spheres of Justice: A Defence of Pluralism and Equality, Basic Books, New York.

Wolff, J. (2011) Ethics and Public Policy: A Philosophical Inquiry, Routledge, London and New York.

\title{
Notes
}

1 For the purposes of this paper, equity theories, equity principles and ethical theories are considered to be synonymous as the focus is more on the application of such theories in the transport sector rather than in identifying their differences.

2 The authors acknowledge the limitations of using household income quintiles as a proxy and anticipate that further research in this field should aim at using more accurate group indicators assuming that relevant data are available (see for example Thornton et al., 2011). These limitations may include the fact that households are in different stages of their income development cycle which may be more important at a micro level rather than a macro level.

\author{
Abbreviations \\ BCR benefit-cost ratio \\ BEV battery electric vehicles \\ CBA cost-benefit analysis \\ cICEV conventional internal combustion engine vehicle \\ ICE internal combustion engine \\ LCV low carbon vehicle \\ ZEV zero emission vehicle.
}

